\title{
Poyang lake water level change trend in nearly 60 years
}

\author{
Ying-Ying Lan \\ Academy of Hydraulic and Ecology Engineering, \\ Nanchang Institute of Technology, \\ Nanchang, China. \\ E-mail:lan-yy@163.com
}

\begin{abstract}
Represented by the Xingzi Station, it was studied that the Poyang Lake water level change trend in nearly 60 years. The improved MK test and homogeneity test are used to detect trend and change points in the series of maximum and minimum water levels. Furthermore, the relationship among extreme water levels, precipitation and human activities are discussed. Some meaningful results are obtained as follows. There are an abrupt change late 1960s and early 2000s about all of the low water level (LWL) and high water level (HWL). This is consistent with the regional precipitation changing trend and human activities. LWL and HWL rose significantly in 1995 2003 and 1982-2002 respectively. The region rainfall has a clear upward trend in the 80's and 90's. Many hydraulic projects play a role such as the Three Gorges Dam after 2000s. Those levels were consistent with the regional precipitation changing trend and human activities.
\end{abstract}

Keywords: Mann-Kendall test; Trend Analysis; Time Series; Poyang Lake 。

\section{Introduction}

In recent years with growing concerns over environmental degradation and about the implications of green-house gases on the environment, researchers and practitioners have frequently applied the non-parametric Mann-Kendall (MK) statistical test[1,2] to detect trend in recorded hydrologic time series such as water level, stream flow, and precipitation time series. Trend analysis has proved to be a useful tool for effective water resources planning, design, and management since trend detection of hydrological variables such as stream flow and precipitation provides useful information on the possibility of change tendency of the variables in the future. The MK test is one of the most popularly applied tests to detect trends in hydrologic time series. Water level change is the lake important hydrological process and dynamic reflection of water balance, that has the important influence to water quality, sediment, aquatic organisms

\footnotetext{
${ }^{*}$ The work reported in this paper was performed under the Science and Technology Department of Jiangxi Province, project number 20151BBG70008.
} 
and so on factors of ecological environment. Poyang Lake as one of the most significant lakes on the earth and the largest fresh water lake of China that water level descending in dry period goes to the extent of leading to drought and many ecological problems. Hydrologic time series contains abound of information on hydrological systems, it is not only evolved previous hydrological events, and can be used to predict future patterns and trends [3].

\section{Background}

Poyang Lake locates at the middle and lower reaches, south bank of Yangtze River, within the northern territory of Jiangxi province, between $115^{\circ} 49^{\prime \prime}-116^{\circ} 46^{\prime \prime}$ East longitude and $28^{\circ} 24^{\prime \prime}-29^{\circ} 46^{\prime \prime}$ North latitude. As one of the few lakes that are still freely connected with the river, it plays an important role in the maintenance of the unique biota of the Yangtze floodplain ecosystem. Ecosystem services in Poyang Lake area mainly refer to the services of ecological systems and the natural capital stocks, which is critical to the functioning of the Earth's life-support system in Poyang Lake area. It means that the ecological, environmental and social benefits from the ecosystem of Poyang Lake area satisfy people [4]. The climate is monsoonal with a mean annual air temperature of $17.2^{\circ} \mathrm{C}$, mean annual evaporation of $1184 \mathrm{~mm}$, and mean annual precipitation of $1482.3 \mathrm{~mm}$. Poyang Lake had been shrinking in dry season when Xingzi station (Figure 1) water level decent from $21.6 \mathrm{~m}$ to $6 \mathrm{~m}$, the water area decent from $5000 \mathrm{~km} 2$ to $600 \mathrm{~km}^{2}$. In winter, the lake resembles a river, retaining a water area only $5 \%$ of its largest area. Undoubtedly, many factors effect on current situation and cause this trend exacerbating, such as demographic developments, anthropogenic, agricultural developments, water resources management and dams, natural and climatic factors. So it is very urgent to analysis changing trend of Poyang Lake water level for proper management and control.

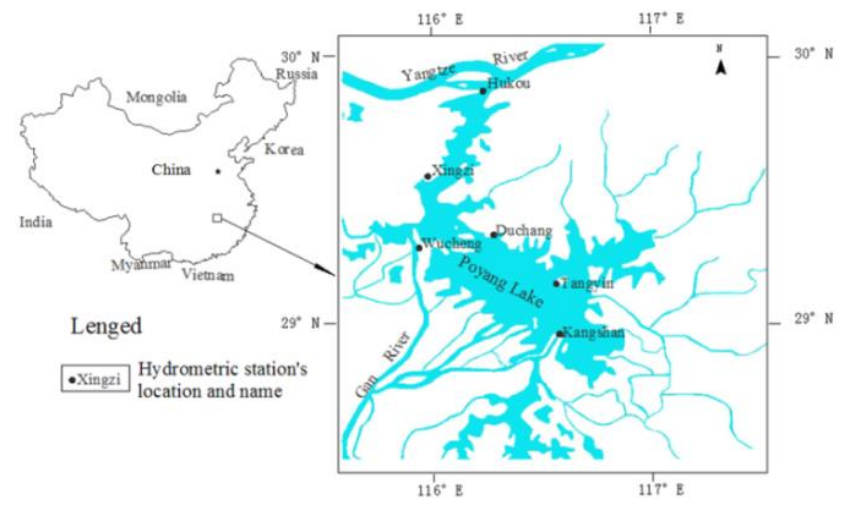

Fig. 1. Poyang Lake hydrological station distribution 


\section{Methodology}

The data is collected during the period from 1953 to 2010. The hydrological parameters (daily data) are collected from the hydrological stations of Jiangxi province, China. The meteorological parameters (daily data) are collected from China Meteorological Department.

The MK test is a non-parametric trend analysis for identifying the increasing and decreasing pattern in time series of the data. It compares the relative magnitudes of sample data rather than the data values themselves [5]. The data values evaluated as ordered time series are compared with all subsequent data values. If a data value from a later time period is higher than a data value from an earlier time period, the statistic $S_{k}$ is incremented by 1 . On the other hand, if the data value from a later time period is lower than a data value sampled earlier, $S_{k}$ is decremented by 0 . The net result of all these increments and decrements yields the final value of $S_{k}{ }^{[6,7,8,9]}$. The $M K$ test statistic $S_{\mathrm{k}}$ is computed as:

$$
\begin{gathered}
S_{k}=\sum_{i=1}^{k} r_{i} \quad(k=2,3, \ldots \ldots n) \\
r_{i}=\left\{\begin{array}{ccc}
+1 & x_{i}>x_{j} \quad(j=1,2, \ldots \ldots i) \\
0 & x_{i} \leq x_{j} \quad(j=1,2, \ldots \ldots i)
\end{array}\right.
\end{gathered}
$$

where $x_{j}$ and $x_{k}$ are the annual values in different years $j$ and $k, j>k$, respectively.

$$
\mathrm{UF}_{\mathrm{k}}=\frac{\left[\mathrm{s}_{\mathrm{k}}-\mathrm{E}\left(\mathrm{s}_{\mathrm{k}}\right)\right]}{\sqrt{\operatorname{Var}\left(\mathrm{s}_{\mathrm{k}}\right)}} \quad(\mathrm{k}=1,2 \ldots \mathrm{n})
$$

$U F_{1}=0, E\left(S_{k}\right), \operatorname{Var}\left(S_{k}\right)$ is the mean and variance of accumulative $S_{k}$. they are independent of each other in $x_{1}, x_{2}, \ldots, x_{n}$. They can be calculated by the next formula if they are with the same continuous distribution.

$$
\begin{gathered}
E\left(s_{k}\right)=\frac{n(n+1)}{4} \\
\operatorname{Var}\left(s_{k}\right)=\frac{n(n-1)(2 n+5)}{72}
\end{gathered}
$$

$U F_{i}$ is the standard normal distribution, is the sequence of statistics calculated flowing the time series. Given the significant level $a$, if $U F_{i}>U_{a}$, indicates the sequence there is an obvious trend. According to the time sequence $x$ reverse $x_{n}, x_{n-1}, \ldots, x_{1}$, Repeat the above process, and made $U B_{k}=-U F_{k}$, $k=n, n-1, \ldots, 1, U B=0$.The advantage of this method is not only the calculation is simple, and can clear the starting time of the mutation, and points out that the mutation area. That is a kind of common mutation detection method. Calculation steps:

(1) Calculate the order column sequence of time series $s_{k}$, and $U F_{k}$ 
(2) Calculating reverse the order of time sequence $s_{k}$, and $U B_{k}$

(3) Given the level of significance, $\mathrm{a}=0.5$, and the critical value $\mathrm{u}_{0.5}=1.96$

That indicates that sequence is on the rise if $U F_{k}$ or $U B_{k}$ greater than zero. Or not it indicates a downward trend. When they exceed the critical line, show that rising or falling trend is obvious. Onset of mutation is outside the range of critical path for the area. If two lines of $U F_{k}$ and $U B_{k}$ appear intersection, and the intersection between the critical paths, then the node corresponding to the moment is the starting time of the mutation.

\section{Analysis and Results}

From the overall change trend, there are an abrupt change late 1960s and early 2000s about all of the low water level (LWL) (Figure 2 (a)) high water level (HWL) (Figure 2 (b)). As for temporal changes, there is a slightly increasing trend in both the LWL and HWL between 1968 2009, but rising trend is not obvious. LWL and HWL presented a downward trend between 1953 1968. LWL and HWL rose significantly in 1995 2003 and 1982-2002 respectively. What's more, the temporal variations of annual LWL are bigger than those of the HWL. The region rainfall has a clear upward trend in the 80's and 90's. Many hydraulic projects play a role such as the Three Gorges Dam after 2000s. Those levels were consistent with the regional precipitation changing trend and human activities.

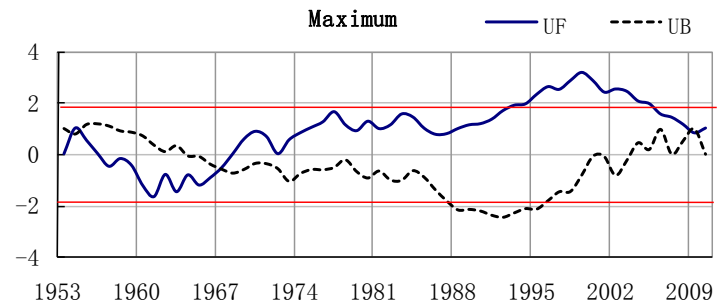

(a)

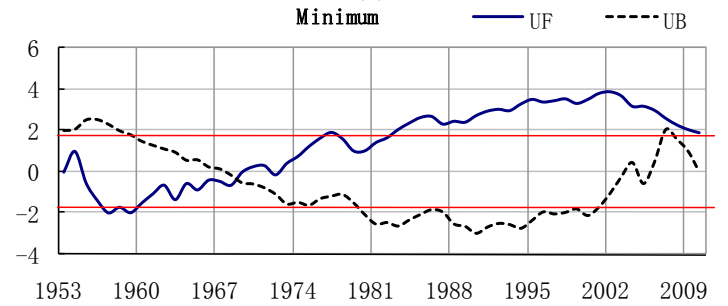

(b)

Fig. 2. Calculation data and MK calculation results

\section{Conclusions}

The paper comes to the conclusion that there are differences between the 
characteristics of extreme water level changes and rainfall variations in the study region, and anthropogenic influence have played more and more important roles in the process of water level changes, while human activities also have a certain impact.

\section{Reference}

1. Mann, H. B.: 1945, 'Nonparametric tests against trend', Econometrica 13, 245-259.

2. Kendall, M. G.: 1975, Rank Correlation Methods, Griffin, London.

3. Wang W S, Ding Jing, Liu Guodong. Artificial neural network nonlinear time series model in hydrologic forecasting [J]. Sichuan Hydropower, China 2000, (19):8 -12.

4. Lan Y Y. (2014). Forecasting performance of support vector machine for the Poyang Lake's water level. Water Science \& Technology, 70, 1488-1496.

5. Gilbert, R. O. (1987). Statistical methods for environmental pollution monitoring. New York: Van Nostrand Reinhold Co.320 pp.

6. Shahid, S. (2011). Trends in extreme rainfall events of Bangladesh. Theoretical and Applied Climatology, 104, 489-499.

7. Shrestha, A. B., Wake, C. P., Mayewski, P. A., \& Dibb, J. E. (1999). Maximum temperature trends in the Himalaya and its vicinity: an analysis based on temperature records from Nepal for the period 1971-94. Journal of Climate, 12, 2775- 2786.

8. Yue, S., Pilon, P., Phinney, B., \& Cavadias, G. (2002). The influence of autocorrelation on the ability to detect trend in hydrological series. Hydrological Processes, 16, 1807-1829.

9. Domonkos, P., Kysel, J. Y., Piotrowicz, K., Petrovic, P., \& Likso, T. (2003).Variability of extreme temperature events in south- central Europe during the 20th century and its relationship with large-scale circulation. International Journal of Climatology, 23, 978-1010. 